\title{
Social Behavior in Organizational Studies
}

\section{KARL E. WEICK and LLOYD E. SANDELANDS}

Theorizing is, among other things, an act of faith. It commits our wordless, prelogical understandings to a select and questionable few categories and relations. And although we may hope these categories and relations are apt descriptors, we can never be sure because our verbalizations are essentially incommensurate with our understandings. For organization theorists committed to ideas about social behavior in organizations, the twenty years of 7TSB pose a formidable test of faith. The journal has consistently called into question and made problematic some of the most basic assumptions about the nature, purposes, meaning, organization, and study of social behavior. From the early papers of Ball (1972) on defining situations, Abercrombie (1974) on sociological indexicality, and Bach (1975) on the essential subjectivity of organization, to the recent papers of Schwalbe ( 1988 ) on role taking, Biela ( 1989 ) on agoral gatherings, and Porpora ( 1989 ) on alternative concepts of social structure, the assault on the sensibilities of organization theory has been unremitting. During this same period, organization theorists have been developing important insights about social behavior that are of potential interest to readers of this journal. By conceiving of social behavior in organizational terms, they have glimpsed aspects of it that are not apparent when that behavior is conceived broadly or in the abstract. And since a great deal of social behavior takes place in organized settings, its meaning and theoretical significance can only be understood by taking its organizational context into account.

It is curious that close ties between organizational studies and studies of social behavior have been slow to develop, in view of the mutual relevance of both bodies of work. That mutual relevance is evident in this excerpt from one of the classics in the field, Burns and Stalker's ( $196 \mathrm{I}$ ) study of innovation in the electronics industry which introduced the influential contrast between organic and mechanistic systems: "[I]n working organizations decisions are made either in the presence of others or with the knowledge that they will have to be 
implemented, or understood, or approved by others. The set of considerations into relevance on any decision-making occasion has therefore to be one shared with others or acceptable to them" (p. I 18 ).

Burns and Stalker are not the only scholars who point to the close affinity between social behavior and organization. Schall (1983), who portrays organizations as communicative phenomena, describes them as "entities developed and maintained only through continuous communication activityexchanges and interpretations-among its participants.... As interacting participants organize by communicating, they evolve shared understandings around issues of common interest, and so develop a sense of the collective 'we' ..., that is, of themselves as distinct social units doing things together in ways appropriate to those shared understandings of the "we"' (p. 560). The idea that interaction is the feedstock from which organization is socially constructed is also visible in Goffman's work: "[A] great deal of the work of organization - decision making, the transmission of information, the close coordinating of physical tasks - is done face to face, requires being done in this way, and is vulnerable to face-to-face effects. Differently put, insofar as agents of social organizations of any scale from states to households, can be persuaded, cajoled, flattered, intimidated, or otherwise influenced by effects only achievable in face-to-face dealings, then here, too, the interaction order bluntly impinges on macroscopic entities" (Goffman, 1983, p. 8).

Intimations of the organizational dimensions of social behavior can be found in Lawrence's (1987) article length review of milestones in organizational research up through 1978 in which he highlights both key methodological issues (e.g., what is appropriate level of analysis) and key theoretical issues (e.g., should the field look for universal or contingent uniformities), or in Scott's ( 1987 ) book length synthesis of an incredibly diverse literature. Similar themes regarding social behavior recur in both sources. For example, sensemaking is important in organizations, not because people necessarily have an inherent need to make sense of activities, but rather because their organizational environment demands and constrains meaningful, justifiable behaviors. Explanations have to be acceptable and credible in that context. Furthermore, equivocality is one of the two major driving forces in organizations, the other being the maintenance and enhancement of subunit status (Hall, i 984, p. 906). Equivocality may result from a lack of clarity concerning cause-effect relationships, from a lack of agreement about preferred outcomes, or both. Thompson and Tuden (1959) have argued that different patterns of equivocality determine whether computation, compromise, judgment, or inspiration will be the more successful strategy of decision making.

Studies of organizations suggest a basic distinction between forms or modalities of social behavior. In so-called "mechanistic systems" social interaction tends to be vertical and people pursue distinct tasks as if they were the subject of a subcontract, whereas in "organic systems", interaction tends to 
be lateral and people pursue tasks that have to be redefined continuously (Burns and Stalker, 196 I, pp. 5-6). From the standpoint of organizational design, the decision about whether to deal with technical complexity through greater complexity of structure as in the case of a mechanistic system, or through greater complexity of the performer as in the case of an organic system, is a watershed event in the process of organizing. "[O]ne way to manage greater task complexity is not to divide the work and parcel it out among differentiated work groups or departments, but to confront the complexity with more highly qualified and flexible performers - with professionals. This response is particularly effective when ( $I$ ) the work is also uncertain, a condition which militates against preplanning and subdivision, and (2) the work does not involve high levels of interdependence among workers. As an example of the latter, the teaching by faculty members in universities, the work of lawyers in law firms, and the work of physicians in clinics as customarily performed tend to involve relatively little interdependence. Whether complexity and uncertainty of work give rise to complex organizations or to complex performers is determined partly by the characteristics of the work itself but is also influenced by the political and social power of the performer group" (Scott, i 987, p. 236).

Even though the social and the organizational weave through one another, investigators repeatedly forget these close ties. Thus, the purpose of this article is to highlight some of the developments in organizational studies over roughly the same period as is represented by the history of $77 S B$, in an effort to draw the readers of $\mathcal{J}$ TSB into the organizational literature as active participants in its construction. Thus, this essay is written to intensify the interchange between theorists of social behavior and theorists of organization, and to improve the quality of both bodies of work. Our discussion is divided into three parts. First, we suggest three routes by which scholars of social behavior can engage the organizational literature and quickly move to the center of many of its issues. Second, we discuss specific topics such as paradigms, structuring, and uncertainty which appear often in both literatures and thus suggest areas of joint interest. And third, we preview a research agenda for studying organizations that is sensitive to issues of social behavior.

\section{ROUTES OF ENTRY INTO THE ORGANIZATIONAL LITERATURE}

Readers of $\mathcal{J} T S B$ who want to sample studies of organizations which highlight social behavior, can enter this literature through at least three routes. These three include compact studies of entire organizations grappling with messy problems, discussions of organizations familiar to academics, and central debates in the field. The following citations have been chosen because they are representative, accessible, presume relatively little familiarity with other organizational work, address topics of contemporary interest (e.g., decline of U.S. organizations), and overlap with interests of $\mathcal{F} \mathcal{T} S B$ readers. 
Although it is difficult to represent complex, organized social entities in the limited space of a journal article, there are several cases where people have done this successfully. These studies weave together observation and theory, provide anchors for further theory development, and encourage comparative analysis. They are the equivalent of strategic research materials (Merton, I 987), because they are longitudinal, highlight process, incorporate sufficient description of structure to link with traditional categories of analysis such as centralization and formalization, and mix together both quantitative and qualitative data.

Hall ( 1984 ) examined the functioning and demise of the Saturday Evening Post based on an evolutionary model of social behavior which gave special attention to coalitional dynamics and power. Mintzberg and McHugh (1985) describe the emergence of strategies and structure in the Canadian Film Board, an organization that is both more dynamic and less formal (i.e., more organic) than the Saturday Evening Post. Meyer's (1982) study of hospitals adapting in three different but equally successful ways to a doctors' strike tackles the difficult issue of discerning the relative contribution to adaptation of structural versus perceptual determinants such as culture. The three styles of adaptation that are documented serve as prototypes for patterns of adaptation often found outside the hospital industry. And Heimer's ( 1985 ) investigation of the ways in which people negotiate an information order that allows the insuring of North Sea oil rigs present a view of social behavior that reaches between organizations. In all of these cases social behavior is conceived as central in the ontogeny of organization, and decisive in determining its eventual outcomes.

An important benchmark in organizational analysis was Allison's (197I) demonstration that U.S. government responses to the Cuban Missile Crisis could be understood from three quite different perspectives: rationality, bureaucratic routines, and power and politics. Subsequent analyses of the same incident, such as that by Anderson ( $19^{8} 3$ ) document in even greater detail the social process of interpretation: "Goals are discovered through a social process involving argumentation and debate in a setting where justification and legitimacy play important roles" (p. 2 I4).

\section{Organizations familiar to academics}

Readers of $\mathcal{J} T S B$ have first-hand familiarity with organizations that publish books, conduct research, educate students and coordinate professionals. That familiarity can be compared with more formal analyses of those same organizations (see Bess, 1984 , for a collection of these studies). For example, Powell ( 1985 ) describes processes by which editors in an academic press make 
their decisions about which manuscripts to publish. What is noteworthy about the account, as is true also of the description of the same activity by Levitt and Nass ( $19^{8} 9$ ), is the sharp discrepancy between formal models of rational decision making and the ways in which decisions are actually made.

What is perhaps most interesting about organizational analyses of universities is that they show them to have distinctive properties that may elude even savvy insiders. One is that the university is not an organization, but a set of organizations (Hage, I980, p. I 2) which means it can be understood best as a federation of organizations, tied together by interorganizational networks, rather than a single organization with a specific objective, such as a school of journalism. Perrow (1984, p. 332) describes universities as complex technologies, which means they share some problems with organizations such as chemical plants and nuclear power generation which are also complex. But the difference is that chemical plants and nuclear power generators are tightly coupled, whereas universities are loosely coupled. This difference means that problems within universities tend to be localized and stay local, to diffuse slowly, and to be unpredictable in their consequences because of these loose ties (Weick, 1976).

The control problems in universities also resemble the control problems found in other dynamic, complex organizations (Kuhn and Beam, 1982, pp. 325-327). In many complex organizations, the top management does not design operating structures. Instead, it designs decision structures. The organization is divided into segmented subunits, and these subunits then design their operating structures. Thus, top management does not actually manage the organization. Instead, they manage the process that manages the organization, and they do so by selecting the people who will be in the decision making group. Top management, in a system of segmented complexity, can no longer tell people what to do and reward them appropriately since individual contributions are concealed within the group product. Thus, top management is in the position of saying, "see what you can do and do your best."

The president of a university is unable to evaluate whether the intellectual products of the faculty are worthwhile. The best research goes the way the researcher wants it to go, not the way the administrator wants it to go. Administrators cannot directly manage the pursuit of hunches so they say, "keep busy and do research." Segments within the university decide key issues, such as teaching and admissions requirements, and the only control presidents have over these subgroups is money and final approval of personnel decisions.

Questions of authority, legitimacy, and insubordination are attenuated in universities, but the same is true in other organizations in which the ties among subsystems are loose and responsibility is delegated to groups rather than to individuals. The structures that result from strong delegation resemble a federation, a market, a holding company, or a confederacy that tries to keep from getting overly organized. 
If academic institutions are also characterized as professional organizations trying to manage a difficult mix of formalization and autonomy, then the large literature on professional organizations, as exemplified in Organ and Greene's (1981) study of tradeoffs between formalization and alienation becomes relevant. An even more proximate academic study is Pfeffer and Moore's ( 1980 ) finding of a positive correlation between the development of an academic department's paradigm and the tenure of the head of that department. Consensus enhances administrative stability.

\section{Central debates in organizational theory}

It is one of the quirks of organizational studies, that the referent is so complex, that perspectives tend to proliferate rather than confront one another in debate. The literature has an even-handed sprawl rather than a contentious focus. However, an influential attempt to map the potential for debate is Astley and Van de Ven's ( 1983 ) summary of prevailing positions and questions in organizational studies using a $2 \times 2$ matrix built around the dimensions, micro/ macro and deterministic/choice.

The guiding questions for analysis, formed by pairing cells within the matrix (1. micro-deter, 2. micro-choice, 3. macro-deter., 4. macro-choice) generates inquiries such as these:

"I. Are organizations functionally rational, technically constrained systems, or are they socially constructed, subjectively meaningful embodiments of individual action? [ $\mathrm{I}$ vs. 2];

2. Are changes in organizational forms explained by internal adaptation or by environmental selection? [ I vs. 3];

3. Is organizational life determined by intractable environmental constraints, or is it actively created through strategic managerial choices? [ $2 \mathrm{vs.}$ 3];

4. Is the environment to be viewed as a simple aggregation of organizations governed by external economic forces, or as an integrated collectivity of organizations governed by its own internal social and political forces? [3 vs. 4];

5. Is organizational behavior principally concerned with individual or collective action? [2 vs. 4 ];

6. Are organization neutral technical instruments engineered to achieve a goal, or are they institutionalized manifestations of the vested interests and power structure of the wider society? [I vs. 4]." (1983, pp. 245-246).

A different, more content-based way to organize the study of organizations is represented by Miller's ( $19^{87}$ ) suggestion that four imperatives drive and organize elements - environment, structure, leadership, strategy. 
There is a set of concepts concerning social behavior which are common to $\mathcal{J T S B}$ and key organizational journals such as Administrative Science Quarterly, Academy of Management Review, Academy of Management Journal, Organizational Studies, and The Journal of Management Studies. Although these concepts are sometimes elaborated in different ways, there is sufficient overlap so that each discussion can potentially inform the other. Concepts which reflect this pattern of parallel development include, paradigm, structuring, uncertainty, and interpretation.

\section{Paradigms}

Organizational researchers such as Brown (1978), Pfeffer ( $19^{82}$ ), and Lodahl and Gordon (1972) view organizations as paradigms, which enables them to focus on organizational processes that are socially constructed, at multiple levels of analysis. An example of this imagery is Pfeffer's description of an organizational paradigm as "a technology, including beliefs about cause-effect relations and standards of practice and behavior, as well as specific examples of these, that constitute how an organization goes about doing things" ( 1982 , pp. 227-228).

An important property of a paradigm is that it is not just a view of the world, but also contains procedures for inquiring about the world and categories to collect the observations that are stimulated by the stylized inquiring procedures. Since organizational paradigms tend to be closed systems, there is an ongoing debate about what it takes to change them. The fact that they are closed means it may take a revolution to blow them apart. But, the fact that they are also grounded in values and meanings, means that gradual shifts can set the stage for its replacement.

Pfeffer concludes that the evidence favors a gradual, processual view of change when paradigms are involved. "Meanings are not questioned and overthrown all at once, rather, actions are taken, often within the dominant paradigm, to solve some small problem, which in turn lead to other problems, other actions, and finally the unraveling of the old system of meaning and its replacement with an alternative paradigm. The role of information in this process is more to serve as an arguing point and to provide data around small problems" (1982, p. 233).

The idea that organizations are paradigms is responsive to Peterson's ( $198 \mathrm{I}$ ) concern that the concept of paradigm has been misrepresented. He argues, for example, that the process of community is crucial to the notion of paradigm, yet it has been neglected. To extrapolate Kuhn, people need to emphasize community and hermeneutics, not normal science and paradigm clash, and this 
is what happens when organizational scholars use the concept. Kuhn asked the question, "How does a community foster a 'relatively unanimous' degree of consensus with regard to its perception of problems and approach to a subject matter" (Peterson, p. 19). Organizational researchers, such as Alan Meyer ( 1982 ) ask a similar question: how is a "group-licensed way of seeing" developed and maintained through the medium of an organizational culture?

Finally, the idea of organizations as paradigms is consistent with efforts to define organizations as purely subjective constructions (e.g., Donnellon, Gray, and Bougon, 1986). These efforts recapitulate some of the arguments in this journal by Bach (1975), who cautions that "In thinking of any social structure as a system of regulating and organizing people's behavior, we must be careful not to abstract the social system from the people who make it up. What is called society is not an autonomous entity ... [it] exists neither 'out there', like tigers or trees, nor in the privacy of people's heads, like wishes and worries. In some sense it is intersubjective" (p. I 89).

\section{Structuring}

Attempts to understand organizations have steadily moved from a preoccupation with statics, to more concern with dynamics, process, and structuring. Mohr ( 1982 ) characterizes this as a shift from variance theories to process theories. Representative descriptions of structuring include statements such as the following. Ranson, Hinings, and Greenwood (1980, p. 2) observe that "the 'rational' panoply of roles, rules, and procedures which make up organizational design is not pregiven in the organization but is the skilled, practical, and retrospective accomplishment of members". Mintzberg (1978) sees structure as bureaucratic momentum which serves as a source of selffulfilling prophecies. Thus, contingency plans have a way of confirming their expectations as when a Special Force created as a contingency finds a way to make itself needed (p. 942).

Taking a different and more subjectivist tack, Starbuck and Nystrom ( $198 \mathrm{I}$, p. 12) view structure as an artifact of postdictive observation and explanation. Echoing this view, Drazin and Sandelands (1990, p. 20) describe social structure as:

... what is seen and named amidst the activity of organization members (i.e., elemental structure). It is both objective and subjective - objective in that it could not exist but for the activities of individuals and the rules that govern their interaction; and subjective in that it could not exist but for a perceiver to identify its form. Because organization is what observers see, there is no separating the organization as object from the perceiving subject, and no telling whether observed structures truly exist. All that can be said for sure is that these structures "appear" to an observer. This means that theories of organizing must take the observer into account, as well as actions and events occurring in the social field. 
These and other theoretical conceptions of structuring in organization studies are also familiar in the pages of 7 TSB. Manicas (1980), for example, identifies social structure with the active doings and conceptions of persons and suggests that they are real in the sense that they constrain, limit, and enable actions. Turner ( 1988 ) outlines a behavioral theory of social structure, based on the six processes of regionalizing, categorizing, ritualizing, stabilizing, normativizing, and routinizing. And, in a very helpful paper, Porpora ( 1989) enriches the discussion of the topic by distinguishing four ways social structure has been conceived - as I) temporally stable patterns of aggregate behavior, 2) lawlike regularities among social facts, 3) systems of relations among social positions, and, following Giddens, 4) as rules and resources. These efforts should help stem the persistent confusion that arises from theorists being unaware that they are talking about different concepts of structure.

Actual descriptions of structuring activity have become increasingly common in the organizational literature. Examples include Lanzara ( 1983 ) on ephemeral organizations, Gronn on talk as the work ( 1983 ) Cowan on problem recognition ( 1986 ), Nutt on decision processes ( 1984 ), Feldman on processes of norm formation ( $\mathrm{I}^{8} 84$ ), and Frederickson ( 1983 ) on processes of strategy formation.

Structuring, as conceptualized in $\mathcal{F T S B}$, often is embodied in the specific imagery of structuration proposed by Giddens (see special issue of March, 1983 ). Shotter ( 1983 ) describes this process succinctly as structuring of both process and product, whereby action in the course of its own performance provides itself with the conditions for further action. Some of the dynamics of this process are illustrated by Smith's ( 1983 ) description of relations between social constructions of meaning and value, and enactments of structured behavior in the pure-bred beef business. The concept and imagery of structuration appears in organizational studies such as the empirical work of Barley ( 1986 ) and Riley ( 1983 ), and in the conceptual work of Dow ( 1988 ) and Ranson, Hinings, and Greenwood ( 1980 ).

\section{Uncertainty}

Uncertainty, such as might be found in a hospital emergency room (Argote, I 982) or in a capricious Hollywood labor market (Faulkner, 1983), is often treated as the master animator of organizational life. Whether the uncertainty is located in the material environment (e.g., Ulrich and Barney, 1984), in the "sensable" environment (Huber and Daft, 1987, p. I 54), or in perception (e.g., Downey and Slocum, 1975) and whether it is defined as ambiguity or equivocality (e.g., Daft and Lengel, I 986), there is agreement that confusion and ignorance dominate organizational life, and that action is often designed to increase meaning and clarity. 
There is also agreement that in organizations different forms of ambiguity are found in different places. For example, top management often doesn't know key issues and people at the bottom have useless technology (Padgett, 1980, p. 586). There is less agreement about which forms of uncertainty dominate which levels in hierarchies. There is also less agreement (see Daft and MacIntosh, 198r) about whether ambiguity in organizations takes the form of equivocality (confusion from multiple meanings requires deeper, qualitative, face to face information processing) or the form of uncertainty (ignorance from insufficient data requires wider, quantitative, formalized information processing).

Efforts to sort out questions such as this are found in representative work by Milliken (1987), McCaskey (1982), and March and Olson (1976). Milliken, who defines uncertainty as the "perceived inability to predict something accurately" (p. 136), argues that it occurs in one of three forms. State uncertainty occurs when people perceive that the environment or one of its components is unpredictable (e.g., how will my competitor react?). Effect uncertainty is the inability to predict how a future state of the environment will affect the organization (e.g., how will an impending hurricane affect us). And response uncertainty is the lack of knowledge of response options or of likely consequences if a specific response choice is made (e.g., what should I do now that the Berlin Wall is down?). McCaskey ( 1982 ), using a more content-based scheme, describes 12 sources of ambiguity in organizations (e.g., multiple conflicting interpretations, roles vague, success measures are lacking). Finally, March and Olson (1976, p. 12) identify four sources of ambiguity at a slightly higher level of abstraction than does McCaskey. Their four include intention: organizations have inconsistent and ill-defined objectives, understanding: unreliable connections between actions and their consequences, history: no single version of past exists, and organization: participation and attention vary.

Regardless of what form uncertainty takes, people who are able to reduce it around issues that are important for the organization, gain power (e.g., Hall 1984, Pfeffer, 1981). Ironically, this relationship between power and uncertainty occurs alongside the equally clear demonstration that the preservation of uncertainty often allows people in organizations to get things done. For example, Eisenberg (1984) argues that strategic ambiguity preserves the impression that people with diverse needs share common understandings, and this unified diversity permits concerted action while preserving varied resources capable of adapting to diverse environments. Similar issues have been raised within the pages of $\mathcal{J} T S B$. For example, Smithson (1985) argues that environmentalists and manufacturers appeal to uncertain knowledge as justification for opposite strategies. Environmentalists argue that uncertainty about the effects of manufacturing processes means we should shut them down, while manufacturers argue that in the face of uncertainty about what is going on, nothing should be changed. Harre ( 1983, p. 71) suggests that vagueness is important in everyday life because it preserves options in social actions. 


\section{Interpretation}

Debates that unfold along the deterministic-voluntaristic axis of the Van de Ven and Astley matrix typically focus on the relative contribution people in organizations make to shaping and creating the reality they face. Voluntaristic views represent variations on the theme that social action is directly tied to the meanings that individuals construct for events which they often have a hand in creating.

First, human beings act toward things on the basis of the meanings that the things have for them. Second, those meanings are directly attributable to the social interaction that one has with [others]. Third, these meanings are created, maintained, and modified through an interpretative process used by the person in dealing with the things he encounters (Fisher, I978, p. I 73 ).

Until recently, organization theory has equated interpretation mainly with decision-making (e.g., Simon, 1945). Less attention has been paid to collateral activities such as finding problems, identifying possible solutions, and justifying decisions after they are made. And still less attention has been paid to interpretations that are not obviously tied to decisions - even momentous ones having to do with the meaning of work, leadership, and ideas and norms of conduct. The processes by which organizational events become translated into categories, and the consequences of this translation, are only beginning to be explored as people pay more attention to organizations as interpretation systems (e.g., Daft and Weick, I984; Isabella, 1990, Jackson and Dutton, 1989). A key element of this developing concern is language; not just because language is necessary for conveying meanings, but also because it is an important "noninterpretational foundation of interpretation in social interaction" (Munch and Smelser, 1987, p. 367 ). Other non-interpretational foundations, which scholars of interpretation often assume without awareness (Burrell and Morgan, 1979, Chapter 7), include authority relationships that assign rights of interpretation, norms of communication, and communication itself. All of these shape the interpretation process.

The dynamic ecology of meaning in organizations is particularly important because it blurs the distinction between map and territory (Korzybski, 1958; Postman, 1986). Since organizations and their environments consist largely of "talk, symbols, promises, lies, interest, attention, threats, agreements, expectations, memories, rumors, indicators, supporters, detractors, faith, suspicion, trust, appearances, loyalties, and commitments, all of which are more intangible and more influenceable than material goods" (Weick, I 985 ; p. i 28), the map often creates the territory it represents. Thus, the map prefigures perception and encourages actions which fulfill the prophecies implicit in that prefiguring. Proactive people in organizations often enact, manipulate, and influence the territories that verify and lend substance to the maps that anticipated them. 
Whereas a concern for interpretation is only now emerging in organization studies, it has been an integral element of the intellectual landscape of $\mathcal{F T S B}$ from its beginning. In particular, the notion that human action is predicated on interpreted meanings rather than objective stimuli has been a central argument in critiques of contemporary experimental and Skinnerian psychologies (e.g., Schultz, 1971; Mishler, 1976; Hales, 1985). In these arguments, to deny a place for meanings in human conduct is to deny the proportions of its humanity and to misrepresent fundamentally its nature and origins. The further argument that meanings are essentially social in nature is represented in writings on ecological theories of social behavior and perception, structuration, as well as more general discussions of theoretical orientation and methodology (e.g., Rubinstein, 1977; Knowles and Smith, 1982; Porpora, 1983). As Schwalbe (1988) points out, to share meanings is to be concerned with role taking, the mutuality of experience, and negotiation, all of which produce an organizational culture which shapes further consensual meanings and action. Indeed, for Bach (1975) intersubjectivity is the essence of organization, there being nothing more to it than that. Thus it is that culture is something an organization is, not something an organization has.

\section{RESEARCH AGENDA FOR ORGANIZATIONAL STUDIES}

Organizational research during the third decade of $\mathcal{J} T S B$ will resemble, in some ways, the research conducted during its first two decades. This resemblance is likely because basic approaches to the study of organizations are likely to remain essentially in their present form. Nevertheless, we believe that there are several issues on which interchange between people interested in social behavior and organizations can lead to theoretical progress. Among these issues, we briefly mention four: I) contexts of construction; 2) micro-macro links; 3) emotion and organization; and 4) the social-ecology of open systems.

\section{Contexts of construction}

Organizational analysts frequently invoke the image that people construct reality, by which they mean create reality. Discussions of realism in 7 TSB, however, raise serious questions about this practice. Those discussions point to the importance of pre-existing symbols, norms and social structures that are "usually unacknowledged and unintentionally reproduced in the course of social life. They are real but virtual" (Isaac, 1990, p.6). Or as Bhaskar (1978, p. I3) suggests, society pre-exists the individual, which means that people may reproduce or transform their world, but not create it. The image of the sculptor or bricoleur reminds the analyst to specify the pre-existing materials with which the person doing construction, works. 
The lesson for organizational theorists is that they should avoid treating the verbs construct, create, reproduce, and transform as synonyms. If environments are reproduced or transformed from preexisting materials, then it becomes important to identify these materials. And this, in turn, suggests that analysts need to give greater weight to tradition, precedent, culture, and history as determinants of construction and interpretation. Mead's insistence that people carry a slice of society around in their heads, has found its way into organizational analysis through the avenue of institutional theory (e.g., Scott, I987), but it has yet to influence those who discuss social construction.

\section{Macro-micro links}

Although Habermas, Giddens, Collins, Munch, Staw, Knorr-Getina, and Ritzer have tried to link micro and macro levels of analysis, the two styles of interpretation are so different as to be discontinuous. Wiley $\left(198_{3}\right)$, who in a mere three pages has written an important summary of this issue, has proposed that Keynes may have been the most successful at doing so, up to now. Among organizational theorists, Chatman, Bell and Staw (1986) have made an inroad on this linkage issue when they identified an overlap between individual and organizational behavior that is seldom acknowledged. They note that when analysts observe individual behavior in organizations, they are actually seeing two entitles: "the individual as himself, and the individual as a representative of his collectivity (which could be the work group or the organization). Thus, the individual not only acts on behalf of the organization in the usual agency sense, but he also acts, more subtly, 'as the organization' when he embodies the values, beliefs and goals of the collectivity. As a result, individual behavior is more 'macro' than we usually recognize, and organization behavior is more 'micro' than is generally acknowledged" (p. $2 \mathrm{I}$ ) .

Mechanisms to link micro and macro action are also implicit in discussion of the ways in which small events can have large effects. For example, at Bhopal (Weick, I988), growing indifference by management led to an increase in the incidence of small errors, which increased the probability that several of these small errors might occur simultaneously, which increased the probability of a complex interaction among several small errors occurring simultaneously, thereby creating a dangerous condition of interactive complexity (Perrow, 1984).

The question of enlargement and amplification is closely related to the issue of emergent events. The interest in chaos theory, organizational learning, autogenesis, and evolved jobs, suggests that much organizational behavior can be understood as the unanticipated, emergent consequences of initially very elementary constraints (see Levitt and Nass, 1989; Masuch and LaPontin's A I extension of Garbage Can model, 1989). Related to this is John Shotter's 
suggestion ( 1983 , p. 29) that a script is not as good a metaphor for interaction as is a seed.

Herbert Simon's (personal communication) revision of the standard laboratory exercise involving wheel and circle networks, suggests a format within which one can think about and investigate, the issue of enlargement and emergent properties. Simon suggested that we should take five people, identified as $\mathrm{A}$ thru $\mathrm{E}$ and have them interact in a wheel network, and take 5 more people identified as $F$ thru $J$ and have them interact in a circle network. Then persons $A$ and $F$ swap places, followed by $B$ and $G$ etc. The swaps continue until the wheel is being run by no one who had this as their initial experience and the same is true for the circle. Since wheel and circle are the prototypes of the mechanistic vs. organic system, the question is, what hybrid forms exist after the swaps have occurred? These hybrids may suggest novel forms of organization that emerge when micro level adjustments are made.

Inroads on micro-macro issues are even possible within the realm of personality theory. An intriguing sidelight on the micro-macro debate derives from Mark Snyder's ( 1987 ) research on the personality variable of selfmonitoring. Findings suggest that high self-monitors behave the way sociologists predict and low self-monitors behave the way psychologists would predict. The behavior of high self-monitors is guided by group norms, roles, and social cues in each situation, which means there is a very low correlation between their attitudes and their behavior. The behavior of low self-monitors, however, is guided primarily by internal, dispositional features such as attitudes, values, and other personality traits which are displayed consistently from one situation to another (Anderson, r990).

\section{Emotion and organization}

Analyses of organizations are dominated by descriptions of cognitive processes - e.g., of perception, judgment, and decision making. Recently, these have been augmented by descriptions of emotional dynamics. There are preliminary suggestions that social behavior and emotion are closely allied, and perhaps in powerful and unexpected ways. This can be seen particularly in two complementary developments within the pages of $77 S B$, which appear promising for organization studies.

First, following the work of Bedford $\left(195^{6-7}\right)$, emotions are coming to be seen as essentially social. According to Armon-Jones (1985, p. 1), emotions are "responses to happenings in the environment which are presented through specific modes of social organization, normative expectations, beliefs and values." This conception follows a constructivist line of reasoning that begins with the idea that emotions are bound-up with actions (Sandelands, 1988), and 
continues with the idea that actions are socially defined and determined. Emotion, therefore, is an aspect of social behavior.

Second, there are suggestions as well that social behavior may be an aspect of emotion. One of these is Pred's (1983) suggestion, following Williams (1965), that social organization expresses a "structure of feeling". Quoting Williams, this structure of feeling corresponds to "a felt sense of the quality of life at a particular place and time, a sense of the ways in which the particular activities combine into a way of thinking and living"' (p. 54). A similar idea is conveyed in Van Maanen and Kunda's ( 1989 ) conception of organization culture as an expression of planned and unplanned emotions of work.

An important implication of the coincidence of emotion and organization is the possibility that emotions play a role in processes of organizing. This is suggested, for example, by Biela's ( 1989 ) analysis of the agoral gatherings that took place during the Papal visits to Poland in 1979. "The emotional reactions which were found" he writes, "could clearly be interpreted in terms of Blumer's ( 1970 ) circular reaction, which is treated in agoral gathering as the central process in crowd formation" (p. $3^{18}$ ). Another illustration may be the temporary organizations described by Lanzara ( 1983 ) that formed and dissolved following a major Italian earthquake. In this crisis environment, ephemeral organizations emerged without design or planning, and seemed to be motivated and held together by the feelings of absorption and control engendered by functionally synchronized interactions. Such examples of fundamental and primeval patterns of organizing may be particularly informative for organizational theory because they reveal an interplay of social behavior and emotion that is crucial but otherwise difficult to spot.

\section{The social-ecology of open systems}

The concept of systems has been a mainstay of organizational analysis, but at the same time, the concept has remained underdeveloped. The concept shows up so often because it reminds organizational analysts to remain attentive to interdependence, self-regulating feedback, complexity, emergent behaviors, micro-macro linkages, responsiveness, and process. The concept also reminds those who try to change organizations that changes spread so any problem need not be tackled head on, that processes fail because feedback is unavailable or delayed or untrustworthy, and that symptoms need not occur in the vicinity of the problem. And the concept has been a mainstay because it enabled a highly diverse set of disciplines including biology, operations research, mathematics, and engineering to contribute ideas that worked, since the imagery of systems provided a common vernacular in which they could be stated.

Despite these advantages, the concept has remained static in its development, due in part to its informal treatment as an axiom of organization - everything 
relates to everything else. Those who treat systems as axiomatic tend to ignore the refinements of systems thinking found in work by Miller (1978) and Katz and Kahn ( 1978 ), under the assumption that their work merely restates the axiom, with embellishments. That is not the case, as has been made clear by Ashmos and Huber (1987) and Pondy and Mitroff (1979). Both sets of investigators show clearly that organizational theorists never took the idea of open systems seriously, a conclusion that is consistent with Scott's (1987) assessment. Ashmos and Huber note that analysts seem reluctant to deal with open systems and instead, keep closing them. That tendency is understandable since rationality works best in a closed, deterministic system, and analysts doggedly impose rational views on organizations despite growing evidence that they are of limited value.

Scott's characterization of the open systems view captures the strong sense in which it departs from rational and natural system views. "The open systems view of organizational structure stresses the complexity and variability of the individual parts - both individual participants and subgroups - as well as the looseness of connections among them. Parts are viewed as capable of semiautonomous action; many parts are viewed as, at best loosely coupled to other parts... The system is multi-cephalous: many heads are present to receive information, make decisions, direct performance. Individuals and subgroups form and leave coalitions. Coordination and control become problematic. Also, system boundaries are seen as amorphous; the assignment of actors or actions to either the organization or the environment often seems arbitrary and varies depending on what aspect of systemic functioning is under consideration ... The emphasis is on organizing as against organization" ( 1987, pp. 90-9l).

An initial move to reanimate open systems imagery is represented by arguments that high variety environments are necessary to sustain open systems (Pondy and Mitroff, 1979, p. 22), and by arguments that interdependence in open systems is a variable rather than a constant (Orton and Weick, I990). The argument for the necessity of variety is based on the assumption that an organization, like the human mind, is of sufficient complexity that it cannot continue to be a mind if its inputs are impoverished (e.g., sensory deprivation). From this perspective, strategies such as buffering, smoothing, and standardization make sense if the organization is a control system but not if it is an open system. It is proposed that a "flood of variety" is in fact what changes an organization from a control system into an open system, a change which might occur when an organization is exposed to a natural disaster or an extreme opportunity (Pondy and Mitroff, 1979, p. 23). Either of these conditions requires that the organization become self-organizing which, if it occurs, then requires continuing environmental variety to maintain this capacity.

In open systems, interdependence is treated as a variable rather than a constant and the question becomes, what are the conditions under which tight vs. loose coupling among system elements is beneficial? Aldrich (1977), for 
example, explored the relative advantages of tight and loose coupling in interorganizational design, when public authorities try to organize a social delivery system such as manpower services to achieve equal opportunity. Tight coupling is beneficial because it negates the tendency of organizations to pursue narrow, sectarian interests. But loose coupling allows maximum responsiveness and innovation to idiosyncratic local conditions. This same dialectic dominates educational organizations where, for example, principals may contribute to a school's well being by loosening couplings to the district office and to other parts of the environment thereby facilitating teachers' work (Firestone, 1985 ). For students of social behavior, the important implication of work with loose and tight coupling is that loose coupling allows for autonomous, self-governing action, independent from other control by other parts of the system, and this allows people to customize and enact environments with which they can cope. In tightly coupled systems, sociability and discretion are lower, alienation is higher and effectiveness suffers. Tight coupling is a potential source of learned helplessness in complex systems. As coupling is loosened, people such as cops (Manning, 1982), nurses (Covaleski and Dirsmith, 1983), judges (Thomas, I983), and teachers (Corwin, 1981 ) are better able to function positively in the face of impossible odds.

An even bolder move to reanimate the open-systems metaphor might be developed from ecological theories of perception and action proposed in JTSB by Knowles and Smith ( 1982$)$; Heft ( 1989 ); and Smith and Ginsburg (1989). These theories extend Gibson's (1979) ideas about the ecological foundations of visual perception to the realms of social perception and behavior, arguing likewise that these are not simply activities performed by actors, but rather are dynamic relations between actors and environments. On this account, environments are not amorphous entities that are perceived and acted upon by cognizing and behaving actors; rather, they are already formed so as to be perceivable in certain ways and to afford certain kinds of actions. The ecological account thus conceives of the environment's affordances as an equal partner to the actor's dispositions, in determining perception and action.

This imagery gives new dimension to the notion of the open system. By stressing the relation between system and environment, it downplays the idea of a boundary between them. There is no longer a closed-system set off from its environment that constructs and processes information about it, but instead a genuinely open system that generates information as a natural by-product of its actions in its environment. To paraphrase Shotter (1983), the organization's response is not $t 0$ an environment but into an environment. Therefore, behavior is explained neither by events taking place exclusively inside the system (e.g., motivation, decision-making), nor by events taking place exclusively outside the system in the environment (e.g., reinforcement contingencies, natural selection). Rather, behavior is everywhere a composite relation. The 
environment's affordances and the system's potentialities together account for the unity of the behavioral act (Heft, 1989).

It is, of course, far too early to say how this conception might fare in organization studies - too many details remain to be worked out. It is one thing to talk of environmental affordances and systemic disposition in the abstract, and something else again to describe them in fine-grained, behavior-specific detail. This is where comprehensive analysis of social behavior will be crucial, because it is ultimately in the interactions of persons that relations between organizations and environments take shape. Nevertheless, and despite the many uncertainties and dangers in translating an ecological perspective to organization studies (see, e.g., Schmitt, 1987), it seems well-worth the effort to try. This perspective could give new impetus and direction to organization theory. Instead of construing organizational behavior in causal terms, it suggests a procedure of decomposition whereby behavior is attributed jointly to dispositions of the system and affordances of the environment. This obviates the need in organization theory for empirically vacuous explanatory verbs such as managerial choice or environmental selection which attempt to locate causes for behavior either inside or outside the system (see, Sandelands and Drazin, 1989).

However it is arrived at, a revitalized concept of organizations as open systems is essential. This is because, increasingly, organizations are no longer what they used to be. As Power (1990, p. 301) has pointed out:

Many firms are no longer structured like medieval kingdoms, walled-off and protected from hostile outside forces. Instead, we find companies involved in an intricate latticework of collaborative ventures with other firms, most of whom are ostensibly competitors.

Karl E. Weick and Lloyd E. Sandelands

University of Michigan

580 Union Drive

Ann Arbor

$\mathrm{MI}_{4}{ }^{8} \mathrm{log}$

\section{REFERENCES}

AberCrombie, N. (1974). Sociological indexicality. Journal for the Theory of Social Behaviour, 4, 89-96.

AlDRICH, H. (1977). Visionaries and villains: The politics of designing interorganizational relations. Organization and Administrative Services, 8, 2340.

Allison, G.T. (1971). Essence of decision. Boston: Little Brown.

ANDERSON, L.R. (199o). Toward a two-track model of leadership training: Suggestions from self-monitoring theory. Small Group Research, 21, 147-167. 
Anderson, P.A. ( 1983 ). Decision making by objection and the Cuban missile crisis. Administrative Science Quarterly, 28, $201-222$.

ARGOTE, L. (I982). Input uncertainty and organizational coordination in hospital emergency units. Administrative Science Quarterly, 27, 420-434.

Armon-Jones, C. (1985). Prescription, explication and the social construction of emotion. Journal for the Theory of Social Behaviour, 15, I-22.

Ashmos, D.D., \& Huber, G.P. (1 987 ). The systems paradigm in organization theory: Correcting the record and suggesting the future. Academy of Management Review, 12, 607-621.

Astley, W.G., \& VAN DE Ven, A.H. ( 1983 ). Central perspectives and debates in organization theory. Administrative Science Quarterly, 28, 245-273.

BACH, K. (1975). Analytical social philosophy. Journal for the Theory of Social Behaviour, 5, 189-2 I4.

BALL, D.W. (1972). The definition of the situation: Some theoretical and methodological consequences of taking W.I. Thomas seriously. Fournal for the Theory of Social Behaviour, 2, $6 \mathrm{I}-74$.

BARLEY, S. ( 1986 ). Technology as an occasion for structuring: Evidence from observations of CAT scanners and the social order of radiology departments. Administrative Science Quarterly, 31, 78-1 08.

BEDFORd, E. (1956). Emotions. Proceedings from the Aristotelian Society, 57.

BEss, J.L., (Ed.) (1984). College and university organization: Insights from the behavioral sciences. New York: New York University Press.

Bhaskar, R. ( 1978 ). On the possibility of social scientific knowledge and the limits of naturalism. Fournal for the Theory of Social Behaviour, 8, 1-28.

Biela, A. (I 989). Agoral gathering: A new conception of collective behavior. Fournal for the Theory of Social Behaviour, 19, 3 I I-336.

Blumer, H. (1970). Outline of collective behavior. In P.R. Evans (ed.), Readings in collective behavior. Chicago: Rand McNally.

BRown, R.H. (1978). Bureaucracy as praxis: Toward a political phenomenology of formal organizations. Administrative Science Quarterly, 23, $365-382$.

Burns, T., \& STALKer, G.M. (196r). The management of innovation. London: Tavistock.

Burrell, G., \& Morgan, G. (1979). Sociological paradigms and organizational analysis. London: Heinemann.

Chatman, J.A., Bell, N.E., \& STaw, B.M. (1986). The managed thought: The role of self-justification and impression management in organizational settings. In H.P. Sims, Jr., \& D.A. Gioia (Eds.). The Thinking Organization ( 9 I-2 I4), San Francisco: Jossey-Bass.

CoRwin, R.G. (Ig8I). Patterns of organizational control and teacher militancy: Theoretical continuities in the idea of "loose coupling." In R.G. Corwin (Ed.), Research in the sociology of education and socialization, (Vol. 2, 26 I29I). Greenwich, Conn: JAI. 
Covaleski, M.A., \& Dirsmith, M.W. ( 983 ). Budgeting as a means for control and loose coupling. Accounting, Organizations, and Society, 8, 323-340.

Cowan, D.A. ( 1986 ). Developing a process model of problem recognition. Academy of Management Review, 11, 763-776.

DAFT, R.L., \& Lengel, R.H. (1986). Organizational information requirements, media richness, and structural design. Management Sience, 32, 554571.

DAFT, R.L., \& Macintosh, N.B. (I98I). A tentative exploration into the amount and equivocality of information processing in organizational work units. Administrative Science Quarterly, 26, 207-224.

DAFT, R.L., \& WEICK, K.E. (Ig84). Toward a model of organizations as interpretation systems. Academy of Management Review, 9, 284-295.

Donnellon, A., Gray, B., \& Bougon, M.G. (ig86). Communication, meaning, and organized action. Administrative Science Quarterly, 31, 43-55.

Dow, G.K. ( 1988 ). Configurational and coactivational views of organizational structure. Academy of Management Review, 13, 53-64.

DoWNey, H.K., \& Slocum, J.W.,Jr. (1975). Uncertainty: Measures, research, and sources of variation. Academy of Management Joumal, 18, 562-578.

Drazin, R., \& Sandelands, L. (1990). Autogenesis and the process of organizing. Unpublished manuscript. University of Michigan, Department of Psychology.

EISENBERG, E.M. (1984). Ambiguity as strategy in organizational communication. Communication Monographs, 51, 227-242.

Faulkner, R.R. ( $\mathrm{I}^{8} 3$ ). Music on demand: Composers and careers in the Hollywood flim industry. New Brunswick, N.J.: Transaction.

Feldman, D.C. (1984). The development and enforcement of group norms. Academy of Management Review, 9, 47-53.

Firestone, W.A. (1985). The study of loose coupling: Problems, progress, and prospects. In A. Kerckhoff (Ed.), Research in sociology of education and socialization (Vol. 5, 3-30). Greenwich, CT.: JAI.

Fisher, B.A. (1978). Perspectives on human communication. New York: Macmillan.

Fredrickson, J.W. ( 1983$)$. Strategic process research: Questions and recommendations. Academy of Management Review, 8, 365-575.

GiBson, J.J. (1 979). The ecological approach to visual perception. Boston: HoughtonMifflin.

Goffman, E. ( $9^{8} 3$ ). The interaction order. American Sociological Review, 48, II 7 .

GRONN, P.C. ( 1983 ). Talk as the work: The accomplishment of school administration. Administrative Science Quarterly, 28, I-2 I.

HAGE, J. (I980). Theories of organizations: Form, process, and transformation. New York: Wiley.

Hales, S. (1985). The inadvertent rediscovery of self in social psychology. Journal for the Theory of Social Behaviour, 15, 237-282. 
HALI, R.I. ( 1984$)$. The natural logic of management policy making: Its implications for the survival of an organization. Management Science, 30, 905927.

HARRE, R. ( 1983 ). Commentary from an ethogenic standpoint. Journal for the Theory of Social Behaviour, 13, 69-73.

HEFT, H. ( 1989 ). Affordances and the body: An intentional analysis of Gibson's ecological approach to visual perception. Journal for the Theory of Social Behaviour, 19, I-30.

HeIMER, C.A. ( 1985 ). Allocating information costs in a negotiated information order: Inter-organizational constraints on decision making in Norwegian oil insurance. Administrative Science Quarterly, 30, 395-41 7. .

Huber, G.P., \& DAFT, R.L. (1987). The information environments of organizations. In F.M. Jablen, L.L. Putnam, K.H. Roberts, \& L.W. Porter (Eds.), Handbook of organizational communication (130-164), Newberry Park: Sage.

ISAAC, J.C. ( I 990). Realism and reality: Some realistic considerations. Journal for the Theory of Social Behaviour, $20,1-32$.

IsABELLA, L.A. (I990). Evolving interpretations as a change unfolds: How managers construe key organizational events. Academy of Management Journal, 33, 7-4I.

JACKson, E.E. \& DutTon, J.E. (1988). Discerning threats and opportunities. Administrative Science Quarterly, 33, 370-387.

KATZ, D., \& KAHN, R. (1978). The social psychology of organizations, and Ed. New York: John Wiley.

Knowles, P.L. \& D.L. SMith ( 1982). The ecological perspective applied to social perception: revision of a working paper. Journal for the Theory of Social Behaviour, 12, 53-78.

Korzybski, A. ( $195^{8}$ ). Science and sanity. $4^{\text {th Ed. Lakeville, Conn.: International }}$ Non-Aristotelian Library Publishing Co.

KuhN, A., \& BEAM, R.D. ( $19^{82}$ ). The logic of organization. San Francisco:JosseyBass.

LANZARA, G.F. ( 1983 ). Ephemeral organizations in extreme environments: Emergence, strategy, extinction. Journal of Management Studies, 20, 71-95.

LAWRENCE, P.R. ( 1987 ). Historical development of organizational behavior. In J.W. Lorseh (Ed.), Handbook of organizational behavior ( I-9). Englewood Cliffs, N.J.: Prentice-Hall.

LevitT, B., \& NAss, C. (I 989 ). The lid on the garbage can: Institutional constraints on decision making in the technical core of college-text publishers. Administrative Science Quarterly, 34, 190-207.

LODAHL, J., \& Gordon, G. (1972). The structure of scientific fields and the functioning of university graduate departments. American Sociological Review, 37, $57-72$.

Manicas, P. ( 1980 ). The concept of social structure. Journal for the Theory of . 
Social Behaviour, 10, 65-82.

ManNing, P.K. (1988). Symbolic communication. Signifying calls and the police response. Cambridge, Mass.: MIT Press.

MARSh, J.G., \& OlSEN, J.P. ( 1976$)$. Ambiguity and choice in organizations. Bergen, Norway: Universitetsforlaget.

Masuch, M., \& LA Potin, P. (1989). Beyond garbage cans: an AI model of organizational choice. Administrative Science Quarterly, 34, 38-67.

MCCASkey, M.B. (1982). The executive challenge: Managing change and ambiguity. Marshfield, Mass.: Pitman.

MERTON, R.K. (1987). Three fragments from a sociologist's notebooks. Annual Review of Sociology, 13, 1-28.

MEYER, D.A. (1982). Adapting to environmental jolts. Administrative Science Quarterly, 27, 515-537.

Miller, D. ( 1987 ). The genesis of configuration. Academy of Management Review, 12, 686-70I.

MilleR, J.G. (1978). Living systems. New York: McGraw-Hill.

Milliken, F.J. (1987). Three types of perceived uncertainty about the environment: State, effect, and response uncertainty. Academy of Management Review, 12, $133^{-1} 43$.

MintzBerg, H. (1978). Patterns in strategy formation. Management Science, 24, 934-948.

MinTzBERG, H., \& McHugh, A. (1985). Strategy formation in an adhocracy. Administrative Science Quarterly, 30, 160-197.

MishleR, E. (1 976). Skinnerism: Materialism minus the dialectic. Fournal for the Theory of Social Behaviour, 6, $2 \mathrm{I}-48$.

MoHR, L.B. (1982). Explaining organizational behavior. San Francisco: JosseyBass.

Munch, R., \& SMelser, N.J. (1987). Relating the micro and macro. In J.C. Alexander, B. Giesen, R. Munch, \& N.J. Smelser (Eds.), The macro-micro link $\left(35^{6}-387\right)$. Berkeley: University of California.

NuTT, P.C. (1984). Types of organizational decision processes. Administrative Science Quarterly, 29, 414-450.

Organ, D.W., \& GreEne, C.N. (1981). The effects of formalization on professional involvement: A compensatory process approach. Administrative Science Quarterly, 26, 237-252.

Orton, J.D., \& WEICK, K.E. (1990). Loosely coupled system: A reconceptualization. Academy of Management Review, 15, 203-223.

Padgett, J.F. (1980). Managing garbage can hierarchies. Administrative Science Quarterly, 25, 583-604.

Perrow, C. (1984). Normal accidents. New York: Basic.

Peterson, G.L. ( $198 \mathrm{I}$ ). Historical self-understanding in the social sciences: The use of Thomas Kuhn in psychology. Fournal for the Theory of Social Behaviour, II, I-30. 
Pfeffer, J. (1981). Power in organizations. Marshfield, Mass.: Pitman.

Pfeffer, J. (1982). Organizations and organization theory. Boston: Pitman.

Pfeffer, J., \& MoORE, W.L. ( 1980 ). Average tenure of academic department heads: The effects of paradigm, size, and departmental demography. Administrative Science Quarterly, 25, 387-406.

Pondy, L.R., \& Mitroff, I.I. (1979). Beyond open systems models of organization. In B.M. Staw (Ed.), Research in organizational behavior (Vol. I, 3-39). Greenwich, CT.: JAI.

PORPORA, D.V. (1983). On the prospects for a nomothetic theory of social structure. Fournal for the Theory of Social Behaviour, 13, 243-264.

POR PORA, D.V. ( 1989 ). Four concepts of social structure. Fournal for the Theory of Social Behaviour, 19, 195-2 12.

Postman, N. (1986). The limits of language. ETC, 43, 227-233.

Powell, W.W. ( 1985$)$. Getting into print: The decision-making process in scholarly publishing. Chicago: University of Chicago Press.

Powell, W.W. (1990). Neither market nor hierarchy: Network forms of organization. In B.M. Staw \& L.L. Cummings (Eds.), Research in Organizational Behaviour, (Vol. I2, 295-336). Greenwich, CT: JAI.

Pred, A. (1983). Structuration and place: On the becoming of sense of place and structure of feeling. Journal for the Theory of Social Behaviour, 13, 45-68.

Ranson, S., Hinings, B., \& Greenwood, R. (1980). The structuring of organizational structures. Administrative Science Quarterly, 25, I-I 7 .

RILEY, P. (1983). A structurationist account of political culture. Administrative Science Quarterly, 28, 41 4-437.

RUBinstein, D. (1977). The concept of action in the social sciences. Fournal for the Theory of Social Behaviour, 7, 209-236.

SANDELANDS, L.E. ( 1988 ). The concept of work feeling. Journal for the Theory of Social Behaviour, 18, 437-457.

Sandelands, L.E., \& Drazin, R. (1989). On the language of organization theory. Organization Studies, 10, 457-477.

SCHALL, M.S. ( 1983 ). A communication - rules approach to organizational culture. Administrative Science Quarterly, 28, 557-581.

Schмiт, B.H. (1987). The ecological approach to social perception: A conceptual critique. Journal for the Theory of Social Behaviour, 17, 26 $1-278$.

Schwalbe, M. (I 988). Role taking reconsidered: Linking competence and performance to social structure. Journal for the Theory of Social Behaviour, 18, $4^{11-436 .}$

Schultz, D. (1971). Psychology: A world with man left out. Fournal for the Theory of Social Behaviour, 1, 99-1 18.

ScotT, W.R. (1987). Organizations: Rational, natural, and open systems. 2nd Ed. Englewood Cliffs, N.J.: Prentice-Hall.

ScotT, W.R. (1987). The adolescence of institutional theory. Administrative Science Quarterly, 32, 493-5II. 
SHOTTER, J. (1973). Prolegomena to an understanding of play. Fournal for the Theory of Social Behaviour, 3, 47-9o.

Shotter, J. (1983). "Duality of structure" and "intentionality" in an ecological psychology. Fournal for the Theory of Social Behaviour, 13, 19-43.

Simon, H.A. (1945). Administrative Behaviour. New York: Macmillan.

SMITH, C. ( 1983 ). A case study of structuration: The pure-bred beef business. Journal for the Theory of Social Behaviour, 13, 3-18.

SmITH, D.L., \& GinsBURG, G.P. (1989). The social perception process: Reconsidering the role of social stimulation. Foumal for the Theory of Social Behaviour, 19, $31-46$.

SMithson, M. ( 1985 ). Toward a social theory of ignorance. Fournal for the Theory of Social Behaviour, 15, $151-172$.

SNYDER, M. (1987). Public appearances, private realities. New York: Freeman.

Starbuck, W.H., \& Nystrom, P.C. (1981). Why the world needs organizational design. Journal of General Management, 6, $3^{-1} 7$.

Thомаs, J. ( 1983$)$. Justice as interaction: Loose coupling and mediations in the adversary process. Symbolic Interactions, 6, 243-260.

Thompson, J.D., \& Tuden, A. (1 959). Strategies, structures, and processes of organizational decision. In J.D. Thompson (Ed.), Comparative studies in administration (195-2 16). Pittsburgh: University of Pittsburgh.

TURNER, J.H. (1988). A behavioral theory of social structure. Fournal for the Theory of Social Behaviour, 18, 355-372.

Ulrich, D., \& BarneY, J.B. (1984). Perspectives in organizations: Resource dependence, efficiency, and population. Academy of Management Review, 9, $47 \mathrm{I}-4^{8 \mathrm{I}}$.

Van MaAnen, J., \& Kunda, G. (1989). "Real feelings": Emotional expression and organizational culture. In L.L. Cummings \& B. Staw (Eds.), Research in organizational behavior (Vol. I I, 43-104). Greenwich, GT: JAI.

WEICK, K. (1976). Educational organizations as loosely-coupled systems. Administrative Science Quarterly, 21, I-19.

WEICK, K. (1985). Sources of order in underorganized systems: Themes in recent organizational theory. In Y.S. Lincoln (Ed.), Organizational theory and inquiry ( $106-136)$. Beverly Hills: Sage.

WEICK, K.E. (1988). Enacted sensemaking in crisis situations. Fournal of Management Studies, 25, 305-31 7 .

Wiley, N. (1983). Macro versus micro interpretation: A note on Porpora's paper. Fournal for the Theory of Social Behaviour, 13, 281-284.

Williams, R. ( 1965$)$. The long revolution. Harmondsworth: Penguin. 